\title{
Isolation of Balamuthia mandrillaris (Free Living Amoeba) from Shatt Al-Arab River in Basrah, South of Iraq
}

\author{
Moker H. M.1 \\ ${ }^{1}$ Department of Laboratory sciences, College of Pharmacy, University of Basrah, Iraq \\ ${ }^{2}$ Department of Biology, College of Science, University of Basrah, Iraq
}

\begin{abstract}
Balamuthia mandrillaris is a free living, opportunistic amoeba was first discovered in 1986 in a mandrill baboon at the Wild Animal Park in California suffered from a neurological disease, later it was associated with many human CNS fatal infection and skin infection all over the world, and it considered to be ubiquitous. We investigate the presence of B. mandrillaris in Shatt Al-Arab, the main river in Basrah south of Iraq, the amoeba was identified morphologically and genetically by PCR. Trophozoite and cyst were observed in culture, the trophozoite with finger like pseudopodia that subdivided into small arms. Rounded cyst of about 13-30 $\mu \mathrm{m}$ surrounded by outer thin wrinkled layer gave the shape of a rose flower. Our finding was the first in Iraq, Balamuthia mandrillaris represent a health hazard in such main river in Basrah.
\end{abstract}

Keywords: Balamuthia mandrillaris, Opportunistic Amoeba, Shatt Al-Arab River, Basrah, Iraq

\section{Introduction}

Balamuthia mandrillaris is an opportunistic freeliving amoebae that causes serious cutaneous infections and fatal encephalitis in human (Siddiqui \& Khan, 2015) and may invade the skin causing extensive skin lesions (Martinez and Visvesvara, 1997). B. mandrillaris infection has been identified in other mammalian species, such as sheep, horses and dogs (Schuster et al., 2009).

B. mandrillaris was first isolated in 1986, from the brain tissue of a mandrill baboon (Papio sphinx) at the San Diego Zoo Wild Animal Park in California that died after a neurological disease (Visvesvara $e t$ al., 1990). Later it was associated with fatal human infections involving the CNS (Anzil et al., 1991). The organism was suggested to enter the body through wounds in the skin that contaminated by soil or by inhalation of cysts carried by wind from soil to the lower respiratory tract (Martinez \& Visvesvara, 1997).

The trophozoite is pleomorphic, uninucleated and binucleated forms are occasionally seen (Lokhande et al., 2015). It characterized by the irregular branching pattern (Visvesvara et al., 1993). Balamuthia trophozoite is similar to Acanthamoeba but larger with a specific morphology (Booton et al., 2003b). Balamuthia cyst possessing three walls that seems to be proteinaceous containing mostly cysteine-rich proteins, no polysaccharides or carbohydrate moieties were detected in the cyst wall; mesocyst seems to contain cellular debris such as lipid granules (Klieščiková, 2013).

B. mandrillaris isolation and cultivation is difficult (Schuster, 2002), but thought to be ubiquitous in the environment (MMWR, 2010). Balamuthia and Acanthamoeba supposed to occupy the same ecological habitats and found naturally in soil (Booton et al., 2003b).The first environmental isolation of this amoeba was from soil by Schuster et al. (2003), and recently was isolated from aquatic environment by Lokhande et al., (2015), it was also recorded from infection of two dogs who swam in pond water previously (Finnine et al., 2007).
Material and Methods:
Water samples were collected in $100 \mathrm{ml}$ sterile cups from Shatt Al-Arab River. The date and site details were fixed for each sample. Within the next 24 hours of collection, 2-3 $\mathrm{ml}$ of each water sample was cultured on non-nutrient agar medium (2\%) in petri-dishes; three replicates were done; incubated at $25 \mathrm{C}^{\circ}$ for three days at least before examination under light microscope.

This article is published under the terms of the Creative Commons Attribution License 4.0 Author(s) retain the copyright of this article. Publication rights with Alkhaer Publications. Published at: http://www.ijsciences.com/pub/issue/2018-01/ DOI: 10.18483/ijSci.1518; Online ISSN: 2305-3925; Print ISSN: 2410-4477 
Purification was done by using a corck-borer like device, designed by Dr. Muslim A. Rahman, that allow to cut a piece of wet agar medium, of about $0.5 \mathrm{~mm}$ diameter under light microscope, Fig.(1), to ensure the presence of targeting amoeba and minimizes the chance for getting other amoeba spp. Then the piece was transported to a fresh wet NNagar medium usually, incubated at $25 \mathrm{C}^{\circ}$ for 3 days at least before growth can be observed. This technique was repeated till obtained a pure isolates.

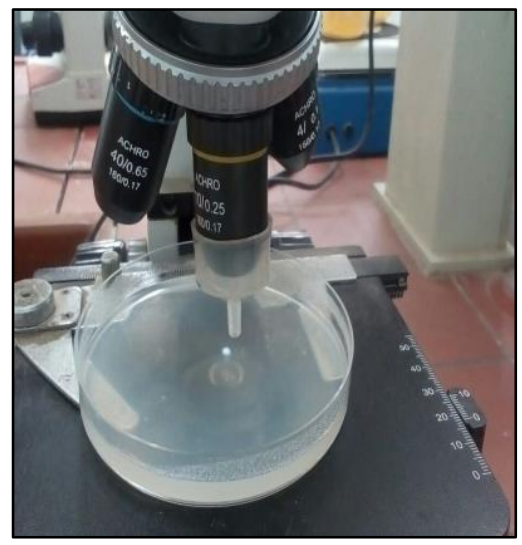

Fig. (1):The crock borer-like devise used in purification.

The identity of amoeba was confirmed, after morphological characterization, genetically by conventional PCR using a set of $B$. mandrillaris specific two primers designed by Booton et al., (2003a): 5Balspec16S (5-

CGCATGTATGAAGAAGACCA-3) and

3Balspec16S (5-

TTACCTATATAATTGTCGATACCA-3)

(manufactured by Alpha DNA). DNA was extracted by using chelex resin according to Iovieno et al. (2011), lysis buffer preparation according to Mirhendi et al. (2006). The PCR product yield was a $1,075 \mathrm{bp}$ from mitochondrial small-subunit-rRNA genes in B. mandrillaris according to the following protocol:

40 cycles of $1 \mathrm{~min}$ at $94^{\circ} \mathrm{C}, 2 \mathrm{~min}$ at $48^{\circ} \mathrm{C}$, and 3 min at $72^{\circ} \mathrm{C}$ followed by a $15 \mathrm{~min}$ final extension at $72^{\circ} \mathrm{C}$. PCR product was electrophoresed on $1.5 \%$ agarose gel and visualized by UV.

\section{Results}

The trophozoite of $B$. mandrillaris measuring 30-65 $\mu \mathrm{m}$, it has a finger-like projections, transparent cytoplasm and a single large nucleus, it moved forward very fast on agar surface by the finger like pseudopodia, the most important identification feature of the trophozoites is the subdivided pseudopodia into small arms, $B$. mandrillaris trophozoite showed an ability to produce pseudopodia from any part of the amoebic body, Fig. (2, 3 and 4). It is difficult to diagnose $B$. mandrillaris trophozoites on slide for the first time, because of narrow surrounded space under cover slips, they took the ordinary ovoid appearance of amoeba then the amoebic body elongated and pseudopodium extended and short finger projections appeared, the pseudopodia continued in elongation and sub-branching while the body mass decreased.

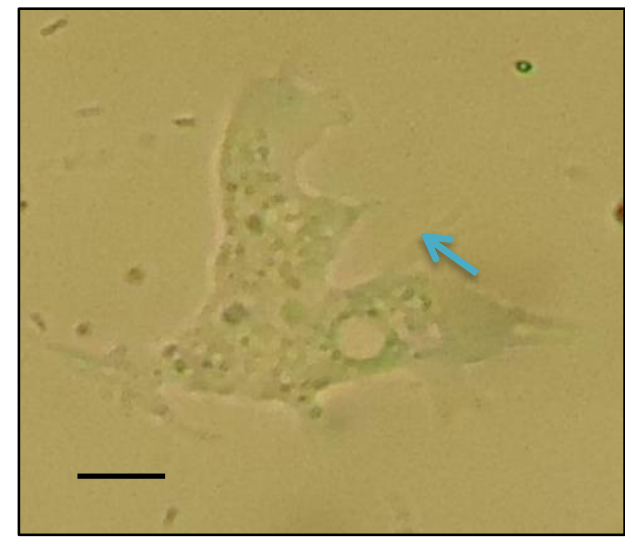

Figure (2): Balamuthia mandrillaris trophozoites (arrow: finger like projections). Scale bar $9.69 \mu \mathrm{m}$.

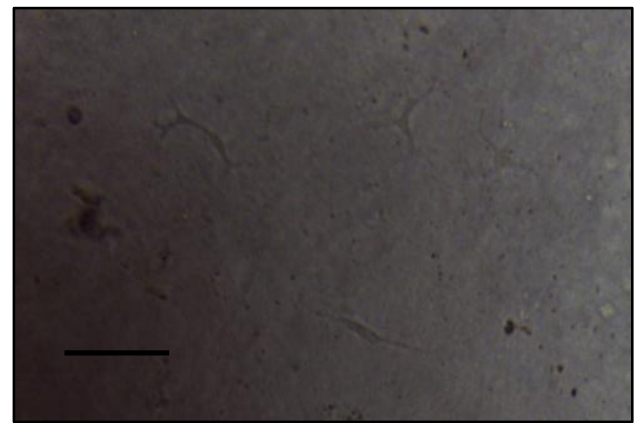

Figure (3): Balamuthia mandrillaris trophozoites on agar. Scale bar $50.6 \mu \mathrm{m}$.

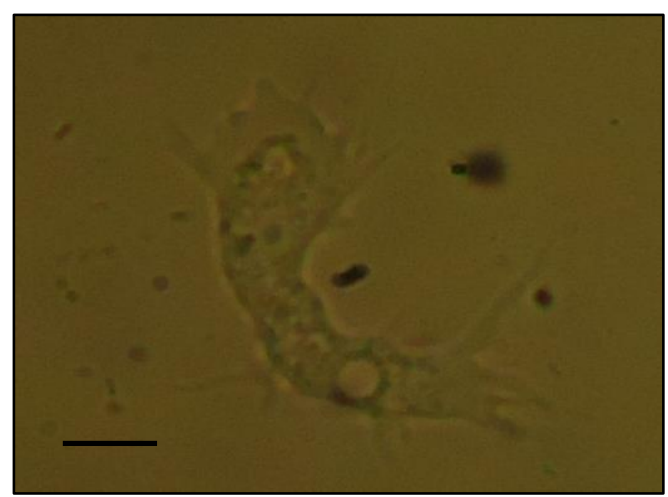

Fig. (4):Balamuthia trophozoite with many pseudopodia. Scale bar $13 \mu \mathrm{m}$.

Cyst of B. mandrillaris, Fig. (5), was more easy to observed in cultures and on slide, it was rounded of about $13-30 \mu \mathrm{m}$ surrounded by inner thick regular rounded membrane and outer thin wrinkled one gave the shape of a rose flower, only the endocyst and ectocyst could be recognized under light 
microscope. The endocyst is rounded without arms and had no pores like Acanthamoeba. Some cysts had rounded smooth outer membrane that may cause a confusing during morphological identification, Fig. (6). The cysts were usually dark brown, which gave the surface of culture media a light brown color like dust.

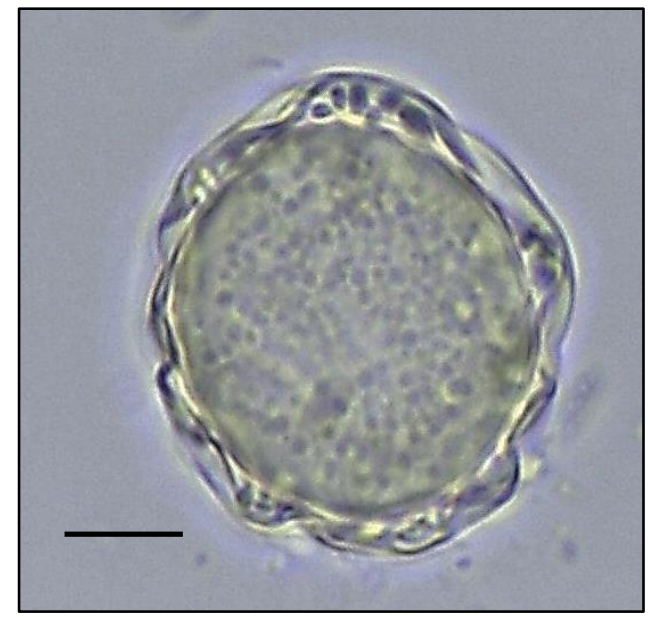

Fig (5): Balamuthia mandrillaris cyst. Scale bar $80.6 \mu \mathrm{m}$

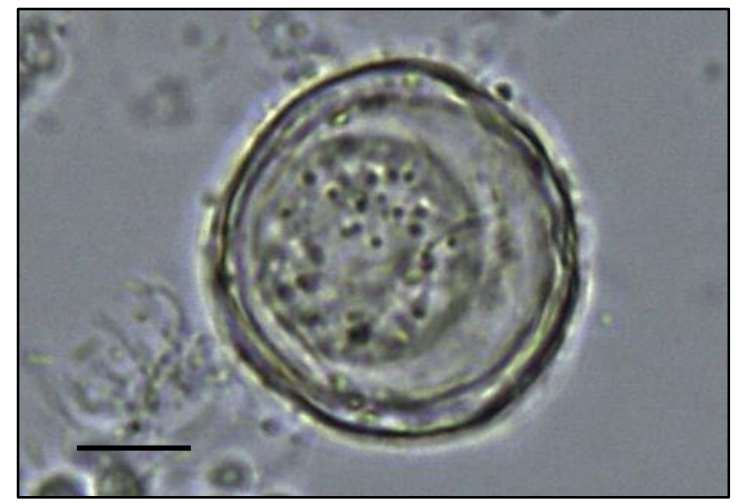

Figure (6): Balamuthia mandrillaris cyst with a rounded smooth outer membrane. Scale bar $6.6 \mu \mathrm{m}$.

Conventional polymerase chain reaction (PCR) using the species specific primer Balspec16S forward and reverse that amplified a portion of mitochondrial rRNA gene yield a 1057 bp product was done to confirm morphological diagnosis, Fig.(7).

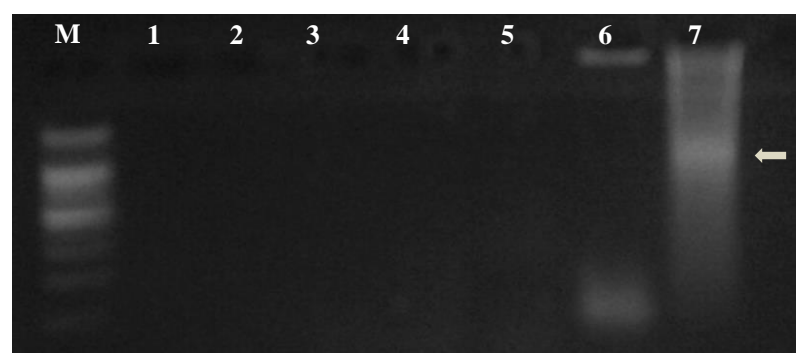

Figure (7): Conventional PCR detecting Balamuthia mandrillaris:
M: 100 bp ladder, lane 7: positive sample of Shatt Al- Arab isolate, (1075 bp) (arrow), lane 2-6: negative samples.

\section{Discussion}

Balamuthia mandrillaris is thought to be ubiquitous in the environment (MMWR, 2010). It was supposed to occupy the same ecological habitats of Acanthamoeba and found naturally in soil (Booton et al., 2003b). Acanthamoeba spp. were also recovered from many different ecologies all over the world, it found in any moist environment rich in bacterial source including: brackish, fresh water and tap water (Visvesvara et al., 2007 a and b). Yousuf et al., (2013) isolated Acanthamoeba and Naegleria fowleri from domestic water and recently $B$. mandrillaris was also isolated from aquatic environment by Lokhande et al., (2015).

The present study is the first in Iraq that detect and isolate this opportunistic free living amoeba from the environment, the primary isolation and purification was depended on cyst mainly, in spite of the large trophozoites size of $B$. mandrillaris, it was hard to observe and identify on agar or slide, the trophozoite is transparent and had a polymorphosim but the irregular branching and subdivided pseudopodia with distinct cyst morphology are considered helpful features in morphological recognition between $B$. mandrillaris and some species of Acanthamoeba.

First isolation of $B$. mandrillaris from environment was from plants pots (Schuster et al., 2003), where organic fertilizer usually used, this may refer to a need for organic resources or could be in associated with the abundant of bacteria and other organisms in such environment that Balamuthia could feed on. The isolation of B. mandrillaris from river water in this study may reveal pollution with organic residues that encouraged their growth, the water sample was poured directly into NN agar medium without filtration or concentration this reflect the high abundance of $B$. mandrillaris in river water. Morphological identification was confirm by PCR used genus specific primers designed by Booton et al. (2003a), that do not amplify DNA from other free living amoebas even the closest Acanthamoeba spp.

B. mandrillaris may serve as a biological host as well as a transmission vector for some pathogenic bacteria (A. Matin et al., 2008). As Shatt Al-Arab river is the main source for domestic water and other usage in Basrah, the presence of $B$. mandrillaris can be considered a health hazard, as $B$. mandrillaris is an opportunistic amoeba and also may harbor some pathogenic bacteria. 


\section{References}

1. Anzil A.; Chandrakant R., Wrzolek M.; Visvesvara G.; Sherand J.; and Kozlowski P. (1991). Amebic meningoencephalitis in a patient with aids caused by a newly recognized opportunistic pathogen, Leptomyxid ameba. Arch Pathol Lab Med. Vol 115: 21-25

2. A. Matin, Siddiqui R., Jayasekera S. and Khan N. A (2008). Increasing Importance of Balamuthia mandrillaris. Clin Microbiol Rev. Vol.: 21(3): 435-448.

3. Booton G. C.; Carmichae J.; Visvesvara G.; Byers T. and Fuerst P. (2003)a. Identification of Balamuthia mandrillaris by PCR assay using the mitochondrial 16s rRNA gene as a target. Journal of clinical microbiology, vol. 41(1): 453455.

4. Booton G. C.; Schuster F. L.; Carmichael J. R.; Fuersta P. A. and Byers T. J. (2003)b. Balamuthia mandrillaris: Identification of clinical and environmental isolates using genus-specific PCR. J. Eukaryot. Microbiol, pp. 508-509.

5. Finnin, P.; Visvesvara G.; Campbell B.; Fry D.; and Gasser R.; (2007). Multifocal Balamuthia mandrillaris infection in a dog in Australia. Parasitology Research, Vol. 100(2): 423-426.

6. Iovieno, A.; Miller, D.; Lonnen, J.; Kilvington, S. and Alfonso, E. C. (2011). Extraction of Acanthamoeba DNA by use of Chelex resin. J. Clin. Microbiol., Vol. 49: 476477.

7. Klieščiková J, (2013). Study of encystation of Balamuthia and Acanthamoeba. Summary of the ph.d. thesis. Charles university in Prague and academy of sciences of the Czech republic.

8. Lokhande S.; More B.; Nikam S.; Sontakke T.; Bandar V. and Bansode V. (2015). Morphological studies on two rare water amoeba Balamuthia mandrillaris and vannella miroides from godavari basin at gangapur and vaijapur international journal of recent scientific research vol. 6(6): 4386-4388

9. Martinez, A. J.; and Visvesvara, G. S. (1997). Free-living, amphizoic and opportunistic amebas. J. Brain Pathol., Vol. 7(1):583-598.

10. Mirhendi, S.H.; Makimura K.; Khoramizadeh M. and Yamaguchi H. (2006). A one-enzyme PCR-RFLP assay for identification of six medically important Candida species. Jap. J. Med. Mycol., Vol. 47: 225-229.

11. MMWR. (2010). Morbidity mortality weekly report. Balamuthia mandrillaris Transmitted Through Organ Transplantation, Mississippi, 2009. 59(36);1165-1170. www.cdc.gov/mmwr/preview/mmwrhtml/

12. Schuster F. L. (2002). Cultivation of Pathogenic and Opportunistic Free-Living Amebas. Clin Microbiol Rev. 15(3): 342-354.

13. Schuster, F. L., Dunnebacke, T. H., Booton, G. C. \& 9 other authors (2003). Environmental isolation of Balamuthia mandrillaris associated with a case of amebic encephalitis. J Clin Microbiol. Vol. 41: 3175-3180.

14. Schuster F. L.; Yagi S.; Gavali S.; Michelson D.; Raghavan R.; Blomquist I.; Glastonbury C; Bollen A. W.; Scharnhorst D.; Reed S. L.; Kuriyama S.; Visvesvara G. S. and Glaser C. A. (2009). Under the Radar: Balamuthia Amebic Encephalitis. Clinical Infectious Diseases Vol. 48:879-87.

15. Siddiqui R.; Khan N. A.(2015). Balamuthia mandrillaris Morphology, biology, and virulence. Vol. 5: 15-22.

16. Visvesara, G.S., Schuster, F.L. \& Martinez, A.J. (1993). Balamuthia mandrillaris, N.G., N.Sp., agent of amebic meningoencephalitis in humans and other animals. J.Euk.Microbiol. Vol. 40:504-514

17. Visvesvara G. S.; Martinez A. J; Schuster F. L.; Leitch G J.; Wallace S. V.; Sawyers T. K. and Anderson M. (1990). Leptomyxid ameba, a new agent of amebic meningoencephalitis in humans and animals. Journal of clinical microbiology, Vol. 28 (12): 2750-2756.

18. Visvesvara G. S.; Booton G. C.; Kelley D. J.; Fuerst P.; Sriram R.; Finkelstein A. and Garner M. M. (2007)a. In vitro culture, serologic and molecular analysis of Acanthamoeba isolated from the liver of a keel-billed toucan (Ramphastos sulfuratus). Vet Parasitol. Vol. 143(1) 74-8.

19. Visvesvara G. S.; Moura H. and Schuste F. L. (2007)b. Pathogenicand opportunistic free-living amoebae: Acanthamoeba spp., Balamuthia mandrillaris , Naegleria fowleri, and Sappinia diploidea. FEMS Immunol. Med. Microbiol. Vol. 50: 1-26.

20. Yousuf F. A., Siddiqui R., Subhani F. and Khan N. A (2013). Status of free-living amoebae (Acanthamoeba spp., Naegleria fowleri, Balamuthia mandrillaris) in drinking water supplies in Karachi, Pakistan. J. Water and Health, V01. 11:371-75. 